\title{
Exploring the Role of Audience Participation and Para-social Interaction on Endorsement Effectiveness in Vlogs: An Abstract
}

\author{
Juha Munnukka and Devdeep Maity
}

\begin{abstract}
In spite of its relevance and importance, scholarship that focusses upon the effectiveness of endorsements in vlogs (blog that uses video as its communication medium) is understudied. This study examines the effectiveness of brand or product endorsements in vlogs with a specific focus upon YouTube as a vlogging platform. Specifically, it assesses how the interactive effect of audience participation and valence influences perceived credibility of the vlogger and consequently results in an effective vlog endorsement. The study explores how perceived credibility of vlogger as a source of brand-related information is constructed and how it affects the effectiveness of the brand- and product-related content published by the vlogger. The study also explores how para-social interaction acts as a mediator to the above relationship.
\end{abstract}

References Available Upon Request

\footnotetext{
J. Munnukka

Jyväskylä University, Jyväskylä, Finland

e-mail: juha.t.munnukka@jyu.fi

D. Maity $(\bowtie)$

Delaware State University, Dover, DE, USA

e-mail: dmaity@desu.edu
} 